\title{
Interaction between Spirosilanes and Lewis Bases: from Coordination to Frustration
}

\author{
Fabrizio Medici, Julien Maury, Gilles Lemière* and Louis Fensterbank* \\ Dedication ((optional))
}

\begin{abstract}
In this work we describe the interaction between Lewis bases, especially $\mathrm{N}$-Heterocyclic Carbenes (NHCs), and hindered neutral silicon derivatives featuring high Lewis acidity. We establish that the formation of normal and abnormal Lewis adducts can be controlled by playing with the acidity of the corresponding tetravalent spiro organosilane. Some DFT calculations allow for gaining insight into the thermodynamics of the NHC-spirosilane interaction featuring various $\mathrm{NHCs}$ differing in size and $\sigma$-donor capacity. We introduce spirosilanes as new Lewis partners in FLP chemistry and some FLPtype reactivities are presented, notably the activation of formaldehyde that could occur with both hindered NHCs and phosphines.
\end{abstract}

The theory of Lewis acid and base is of great importance and has contributed to the development of the twentieth century chemistry. The non-interaction of sterically demanding Lewis pairs has been known for nearly seventy years. ${ }^{[1]}$ In 2006 , the group of Stephan has achieved a major breakthrough demonstrating that the unquenched properties of a hindered Lewis pair could be used to reversibly activate bonds of small molecules. ${ }^{[2]}$ This intriguing concept has opened the gate of new types of reactivity, notably the metal-free splitting of hydrogen and since then many new Lewis partners have proven to exhibit such Frustrated Lewis Pair (FLP) properties. ${ }^{[3]}$ Interestingly, a thorough survey of the published literature would probably show that the chemical variation on FLPs is relatively limited and mainly confined to Group 13 elements such as boron and aluminium derivatives for the acid component, among which $\mathrm{B}\left(\mathrm{C}_{6} \mathrm{~F}_{5}\right)_{3}$ remains predominant. ${ }^{[4]}$

Few silicon-based Lewis acids have been involved for that purpose and most of them are silyliums derivatives, ${ }^{[5]}$ which are isolobal and isoelectronic to boranes and alanes. For instance, the group of Müller reported that hindered triarylsilyliums were able to activate hydrogen in the presence of a hindered phosphane (Scheme1). ${ }^{[5 h]}$ Few years later, the group of Ashley demonstrated that the isolable Lewis adduct formed between ( $i$ $\mathrm{Pr})_{3} \mathrm{Si}^{+}$and $\mathrm{P}(t-\mathrm{Bu})_{3}$ was also able to split hydrogen. ${ }^{[5 \mathrm{e}]}$ Concerning neutral silane species, to the best of our knowledge, the only example has been reported by the group of Mitzel with an intramolecular system $\left(\mathrm{C}_{2} \mathrm{~F}_{5}\right)_{3} \mathrm{SiCH}_{2} \mathrm{P}(t-\mathrm{Bu})_{2}$ which can form a stable adduct with carbon dioxide (Scheme 1$).{ }^{[6]}$ Aside from this intramolecular example, no other tetravalent neutral silicon system has been shown to exhibit FLP properties so far.

[a] Fabrizio Medici, Julien Maury, Dr. Gilles Lemière, Prof. Louis Fensterbank

Sorbonne Université,CNRS, Institut Parisien de Chimie Moléculaire, 4 Place Jussieu, CC 229, 75252 Paris Cedex 05 (France)

E-mail: gilles.lemiere@ sorbonne-université.fr, louis.fensterbank@sorbonne-université.fr

Supporting information for this article is given via a link at the end of the document.((Please delete this text if not appropriate))

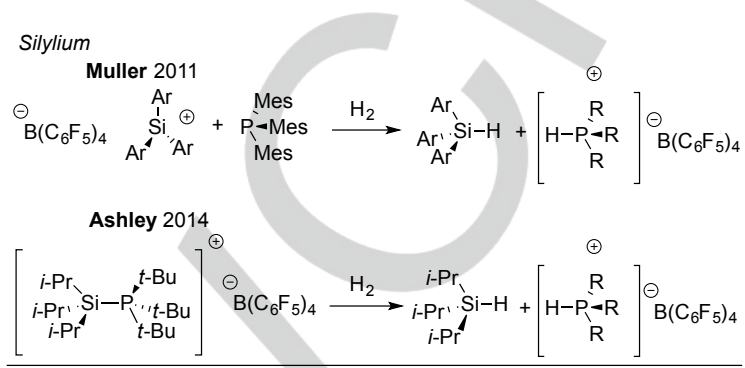

Neutral silane

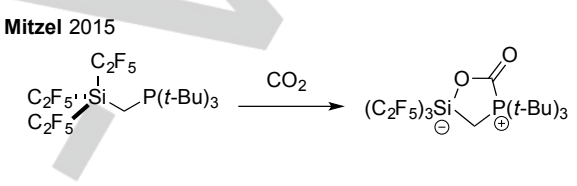

Scheme 1. Silicon-based FLPs for the bond activation of small molecule activation

Our group has been interested in the reactivity of Martin's spirosilane $1,{ }^{[7]}$ a peculiar tetravalent organosilane featuring two hexafluorocumyl alkoxy ligands that is known to possess good Lewis acid properties and lead to stable pentavalent species in the presence of various charged nucleophiles ${ }^{[8]} \mathrm{A}$ hexavalent complex with phenanthroline was also isolated. ${ }^{[9]}$ Recently, we demonstrated that using low sterically-demanding NHCs such as IMe $(R=M e)$ and IMes $(R=$ Mes $)$, the interaction with the Martin's spirosilane 1 was strong and in these cases classical Lewis adducts of type $\mathbf{2}$ were formed in which the silicon moiety displayed a trigonal bipyramidal geometry. ${ }^{[10]}$

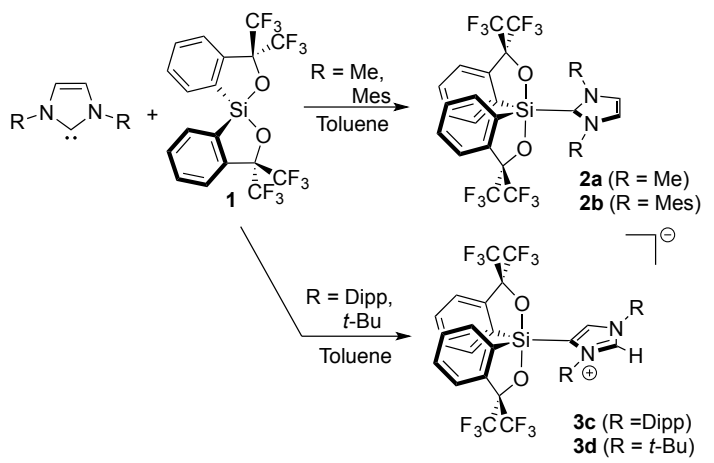

Scheme 2. Interaction between Martin's spirosilane and NHCs (Mes = 2,4,6trimethylphenyl, Dipp $=2,6$-diisopropylphenyl $)^{[10]}$

In sharp contrast, with more encumbered Lewis bases such as hindered NHCs, NMR monitoring revealed that no such interactions with 1 occurred and therefore we were in the 
presence of FLPs (Scheme 2). In this case, the system evolves towards the formation of a stable abnormal adduct of type 3 . $^{[11]}$

Interestingly, at high temperature in toluene, the classical Lewis adduct $\mathbf{2 b}$ formed between IMes and spirosilane $\mathbf{1}$, rearranges to afford the abnormal adducts $\mathbf{3 b}$ (Scheme 3 ). This normal-toabnormal adduct rearrangement has already been observed with metal complexes $^{[12]}$ such as trialkylgallium ${ }^{[13]}$ or aluminum. ${ }^{[14]}$ However it usually occurs with bulkier NHCs such as IPr or ItBu which could attest for the good Lewis acidity of 1 but also its steric hindrance.

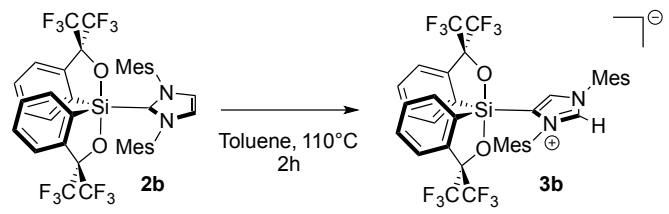

Scheme 3. Interconversion of NHC adduct $\mathbf{2} \mathbf{b}$ into the abnormal adduct $\mathbf{3 b}$.

At this stage, we wondered whether we could tune the reactivity of spirosilane 1 by introducing electron-withdrawing groups, namely $\mathrm{CF}_{3}$ groups, on the aromatic scaffolds. In that case, it would be interesting to evaluate the influence of these substituents on the electrophilic character of the silicon atom and also to see if different behaviors can be observed when confronted with hindered NHCs. On the other hand, we were curious to assess the FLP character in the use of spirosilanes as new Lewis acid partners for the activation of small molecules.

Firstly, the spirosilane analogue 4 bearing $\mathrm{CF}_{3}$ groups on the aryl rings was readily obtained by using known procedure. ${ }^{[8 a]}$

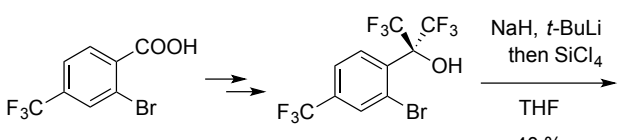

$40 \%$

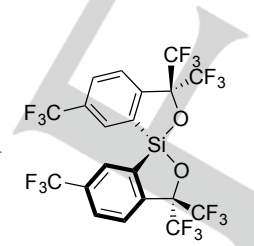

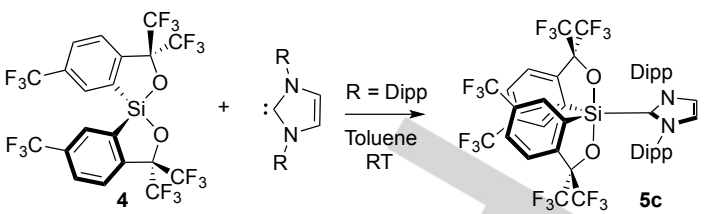

${ }_{3} \mathrm{CCF}_{3} \quad 5 \mathrm{c}$

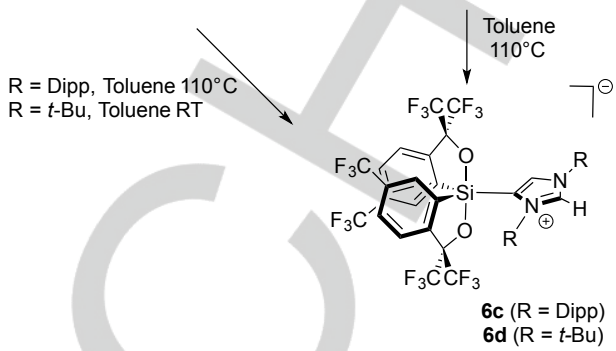

Scheme 5. Interaction between spirosilane $\mathbf{4}$ and hindered NHCs

The structure of the abnormal adduct $\mathbf{6} \mathbf{d}$ could be confirmed by $X$-ray diffraction analysis (Figure 1). In this structure, the $\mathrm{Si}-\mathrm{C}_{\mathrm{NHC}}$ distance is about $1.93 \AA$ which is shorter than the one observed in classical adducts such as $\mathbf{2 a}$ and $\mathbf{2 b}$ (about 1.96 $\AA$ ) ${ }^{[10]}$ This can be attributed to the stronger $\sigma$-donor character of mesoionic $\mathrm{NHC}$ compared to Arduengo-type $\mathrm{NHC}^{[17]}$ In addition, the trigonal bipyramidal geometry of the pentacoordinated silicon moiety is slightly distorted featuring a large O-Si-O angle of $187.0^{\circ}$ probably due to the steric congestion.

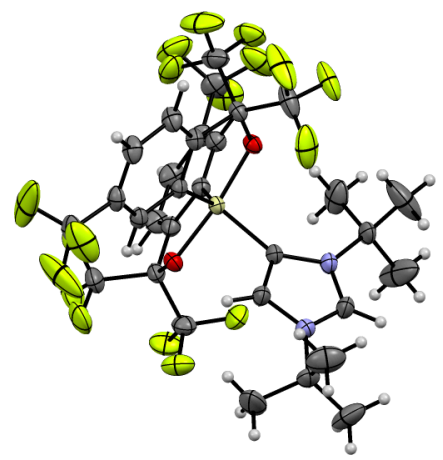

Figure 1. X-Ray crystal structure of 6d (CCDC 1905664)

Scheme 4. Synthesis of spirosilane $\mathrm{CF}_{3}$-analogue 4

To gain further insight into the thermodynamics of the NHCssilanes interactions, we performed DFT calculations at the B3LYP and M05-2X levels and the $31 \mathrm{G}^{* *}$ basis set using the Gaussian09 program. The geometrical parameters obtained with the M05-2X method fit well with the X-Ray crystallographic structures with notably a very good estimation of the $\mathrm{Si}-\mathrm{C}_{\mathrm{NHC}}$ lengths (Table 1). Conversely, the B3LYP method underestimated the interaction between the two partners and gave a longer calculated $\mathrm{Si}-\mathrm{C}_{\mathrm{NHC}}$ bond length. A difference of about $15-20 \mathrm{kcal}^{\mathrm{mol}}{ }^{-1}$ was observed between the two methods for all enthalpies of adduct formation probably due to the better appreciation of the dispersion factors with M05-2X. ${ }^{[19]}$ Nevertheless some trends can be stressed from both methods. It turned out that the formation of the normal adducts 2 between NHCs and 1 was highly dependent on the steric bulk on the $\mathrm{NHC}$. The exothermicity of the Lewis adducts formation indeed decreased by $20 \mathrm{kcal}^{\mathrm{mol}}{ }^{-1}$ between $\mathbf{2 a}$ (from dimethyl IMe) and 2c (from IPr) and about $25 \mathrm{kcal}^{\mathrm{mol}} \mathrm{l}^{-1}$ between 2a and 2d (from ItBu NHC). A Gibbs free energy $\left(\Delta G^{\circ}{ }_{298}\right)$ of $0.5 \mathrm{kcal} . \mathrm{mol}^{-1}$ for the 
formation of $\mathbf{2} \mathbf{d}$ indicates that in this case the adduct formation is endergonic which is fully consistent with our experimental findings. In addition, a high charge transfer of about 0.45 from all $\mathrm{NHCs}$ to silane 1 has been deduced from the NBO analysis. The gain of electron density is mainly redistributed to the apical bistrifluoro alkoxy ligands while the charge at the silicon remains approximately unchanged (from +1.21 to +1.15 ).

Table 1. Thermodynamic parameters obtained by DFT calculations for the formation of normal adducts. Distances are given in $\AA$ and energies in kcal.mol ${ }^{-1}$.

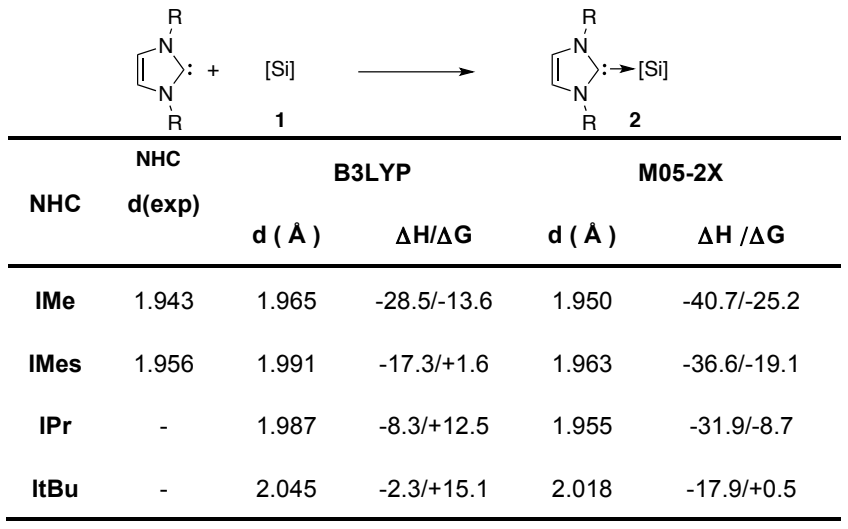

The energy corresponding to the formation of the normal adduct between the $\mathrm{CF}_{3}$ analogue 4 and $\operatorname{IPr}$ was also calculated at the M05-2X level of theory (Scheme 6). Interestingly, the Gibbs free energy is much more exergonic by about 10 units than the one calculated for spirosilane $1\left(-18.2 \mathrm{vs}-8.7 \mathrm{kcal}^{\mathrm{mol}}{ }^{-1}\right)$. This result is in good agreement with the experimental result. Indeed, the classical adduct $5 \mathrm{c}$ can effectively be formed with $\mathbf{4}$ and not with the less acidic spirosilane 1.

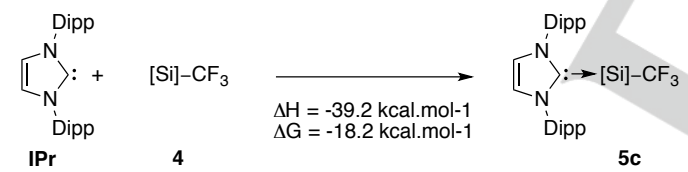

Scheme 6. Calculated interaction between $\mathrm{CF}_{3}$-analogue 4 and $\operatorname{IPr}$ at the M05-2X/31G**level of theory

Regarding abnormal adducts, the calculated $\mathrm{Si}-\mathrm{C}_{\mathrm{NHC}}$ bond length of compound $\mathbf{3 c}$ is longer with both methods than the one deduced from the $\mathrm{X}$-ray structure, which indicates an overall underestimation of the bond strength and consequently of the aNHC-Si interaction. Interestingly and also fully consistent with our results, calculations showed that the abnormal adducts $3 \mathrm{c}$ and $\mathbf{3 d}$ are more stable than the corresponding normal adducts 2c and 2d (Table 2).
Table 2. Thermodynamic parameters obtained by DFT calculations for normal to-abnormal adducts interconversion. Energies are given in $\mathrm{kcal}^{\mathrm{mol}}{ }^{-1}$.<smiles>[R]N1C=CN([Hg])C1=[SiH2]</smiles>

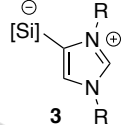

\begin{tabular}{|c|c|c|c|c|c|}
\hline \multirow{2}{*}{$\begin{array}{c}\text { NHC } \\
-\mathrm{Si}\end{array}$} & \multirow{2}{*}{$d(\exp )$} & \multicolumn{2}{|c|}{ B3LYP } & \multicolumn{2}{|c|}{ M05-2X } \\
\hline & & $d(\AA)$ & $\Delta \mathrm{H} / \Delta \mathrm{G}$ & d ( $A)$ & $\Delta \mathbf{H} / \Delta \mathbf{G}$ \\
\hline $3 a$ & - & 1.940 & $8.8 / 7.2$ & 1.926 & $10.8 / 9.41$ \\
\hline $3 b$ & - & 1.954 & $0.1 /-1.8$ & 1.936 & $6.2 / 5.6$ \\
\hline $3 c$ & 1.910 & 1.961 & $-3.7 /-4.8$ & 1.926 & $6.4 / 1.1$ \\
\hline $3 d$ & - & 1.959 & $-11.8 /-13.9$ & 1.936 & $-8.0 /-10.4$ \\
\hline
\end{tabular}

We then examined the behavior of 1 and 4 towards bulky phosphines such as tri-isopropyl and tri-tert-butyl phoshines. No interactions were detected by NMR spectroscopy, suggesting FLP systems in all these cases or a very weak degree of interaction. In order to ascertain a FLP type of behavior with bulky NHCs and phosphines, we looked at the possible activation of various substrates. Unfortunately, the Lewis acid partners 1 and even more acidic 4 proved to be inefficient for the activation of $\mathrm{H}_{2}$ and $\mathrm{CO}_{2}$ in the presence of hindered bases. Nevertheless, activation of formaldehyde ${ }^{[20]}$ was possible with the sterically encumbered IPr NHC and triisopropylphosphine. In these cases, the three-component zwitterionic adducts 7-10 could be isolated (Scheme 7).

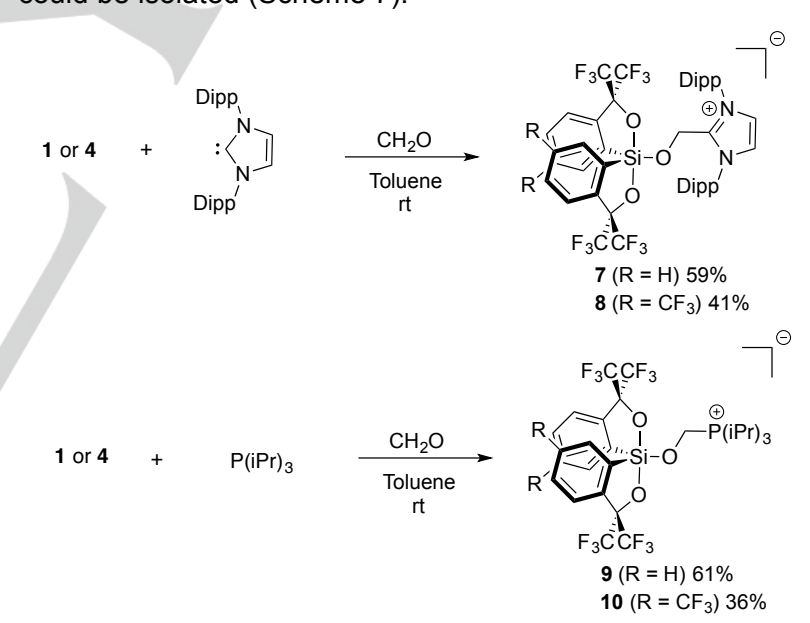

Scheme 7. FLP type reactivities using spirosilanes $\mathbf{1}$ and $\mathbf{4}$ as Lewis acid partners

A XRD structure of $\mathbf{9}$ was obtained and confirmed the insertion of the aldehyde component into the FLP system (figure 2).

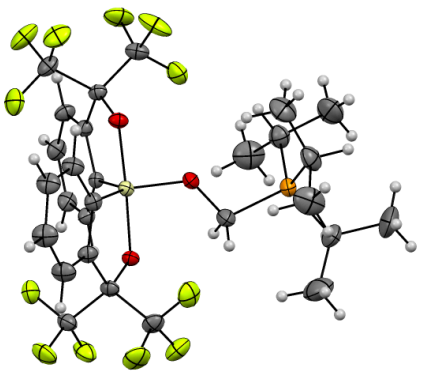

Figure 2. X-Ray crystal structure of 9 (CCDC 1523671) 
Finally, the Lewis partners 1 and the hindered tri-tert-butyl phoshine was used for the activation of alcohols such as benzylic alcohol to form benzyloxysilicate 11 (Scheme 8).

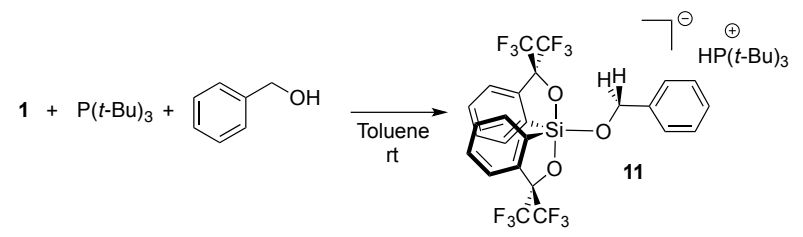

Scheme 8. Synthesis of benzyloxysilicate 11. TMP (1,1,5,5tetramethylpiperidine)

Adduct $\mathbf{1 0}$ was fully characterized by NMR. It notably displayed by ${ }^{1} \mathrm{H}$ NMR an $A B$ system with a large splitting of the two diastereotopic benzylic protons ${ }^{[21]}$ highlighting the intrinsic chirality of the spirosilane moiety. This interesting feature potentially opens the way for further FLP - based asymmetric ${ }^{[22]}$ transformations using chiral spirosilane analogues. ${ }^{[23]}$

To conclude, we have shown that the Martin's spirosilane and its $\mathrm{CF}_{3}$-analogue possess a high Lewis acidity along with a sufficient hindrance that allow for hampering the interaction with hindered Lewis bases. For the NHCs series, we established that the formation of the normal Lewis adduct over the abnormal adduct could be favored by only increasing the Lewis acidity of the tetravalent organosilane. The thermodynamics of these $\mathrm{NHC}$-silane interactions were studied by DFT calculations that gave some trends in accordance with the experimental findings. Finally, a FLP character was unambiguously evidenced in several diagnostic reactions such as the activation of benzylic alcohol and formaldehyde. Further applications of Martin's spirosilane and congeners in FLP chemistry are now under active scrutiny in our laboratory.

\section{Acknowledgements}

We thank Sorbonne Université, CNRS and PSL* (Ph.D. grant to FM) for their financial supporting. We are grateful to Geoffrey Gontard and Jérémy Forte for the XRD analyses.

Keywords: Spirosilane $•$ Lewis acid $•$ Pentavalent silicon $\bullet$ FLP

[1] a) H. C. Brown, H. I. Schlesinger, S. Z. Cardon, J. Am. Chem. Soc 1942, 64, 325; b) H. C. Brown, B. Kanner, J. Am. Chem. Soc. 1966, 88 986; c) G. Wittig, H. G. Reppe, T. Eicher, Liebigs Ann. Chem. 1961 643, 47; d) W. Tochtermann, Angew. Chem., Int. Ed. 1966, 5, 351.

[2] a) G. C. Welch, R. R. San Juan, J. D. Masuda, D. W. Stephan, Science 2006, 314, 1124; b) Welch, G. C.; Stephan, D. W. J. Am. Chem. Soc. 2007, 129, 1880; c) P. A. Chase, G. C. Welch, T. Jurca and D. W. Stephan, Angew. Chem., Int. Ed. 2007, 49, 8050; d) D. W. Stephan, Chem. Commun. 2010, 46, 8526

[4] For leading recent reviews, see: a) D. W. Stephan, Acc. Chem. Res 2015, 48, 306; b) D. W. Stephan, G. Erker, Angew. Chem. Int. Ed. 2015 54, 6400; c) D. W. Stephan, J. Am. Chem. Soc. 2015, 137, 10018; d) J. Paradies, Angew. Chem. Int. Ed. 2014, 53, 3552.
[4] a) J. R. Lawson, R. L. Melen, Inorg. Chem. 2017, 56, 8627; b) Erker, G.G. Erker, Dalton Trans. 2005, 1883; c) W. E. Piers, A. J. V. Marwitz, L. G. Mercier, Inorg. Chem. 2011, 50, 12252.

[5] a) W. Nzahou Ottou, E. Conde-Mendizabal, A. Pascual, A.-L. Wirotius, D. Bourichon, J. Vignolle, F. Robert, Y. Landais, J.-M. Sotiropoulos, K. Miqueu, D. Taton, Macromolecules 2017, 50, 762; b) N. Wolff, G. Lefèvre, P. Thuéry, T. Cantat, ACS Catal. 2016, 6, 4535; c) M. F. Silva Valverde, E. Theuergarten, T. Bannenberg, M. Freytag, P. G. Jones, M. Tamm, Dalton Trans. 2015, 44, 9400; d) S. Weicker, D. W. Stephan, Chem. Eur. J. 2015, 21, 13027; e) T. J. Herrington, B. J. Ward, L. R. Doyle, J. McDermott, A. J. P. White, P. A. Hunt, A. E. Ashley, Chem. Commun. 2014, 50, 12753; f) A. Schäfer, M. Reissmann, A. Schäfer, M. Schmidtmann, T. Müller, Chem. Eur. J. 2014, 20, 9381; g) M. Reissmann, A. Schäfer, S. Jung, T. Müller, Organometallics 2013, 32, 6736; h) A. Schäfer, M. Reissmann, A. Schäfer, W. Saak, D. Haase, T. Müller, Angew. Chem. Int. Ed. 2011, 50, 12636; i) G. R. Whittell, E. I. Balmond, A. P. M. Robertson, S. K. Patra, M. F. Haddow, I. Manners, Eur. J. Inorg. Chem. 2010, 3967.

[6] B. Waerder, M. Pieper, L. A. Körte, T. A. Kinder, A. Mix, B. Neumann H.-G. Stammler, N. W. Mitzel, Angew. Chem., Int. Ed. 2015, 54, 13416

[7] a) E. F. Perozzi, J. C. Martin, J. Am. Chem. Soc. 1979, 101, 1591; b) E. F. Perozzi, R. S. Michalak, G. D. Figuly, W. H. Stevenson, D. Dess, M. R. Ross, J. C. Martin, J. Org. Chem. 1981, 46, 1049.

[8] For recent reports, see: a) H. Lenormand, V. Corcé, G. Sorin, C. Chhun, L.-M. Chamoreau, L. Krim, E.-L. Zins, J.-P. Goddard, L. Fensterbank, J. Org. Chem. 2015, 80, 3280; b) N. Kano, K. Sasaki, H. Miyake, T. Kawashima, Organometallics 2014, 33, 2358; c) H. Lenormand, J.-P. Goddard, L. Fensterbank, Org. Lett. 2013, 15, 748; d) N. Kano, H. Miyake, K. Sasaki, T. Kawashima, N. Mizorogi, S. Nagase, Nature Chem. 2010, 2, 112.

[9] Interaction of $\mathbf{1}$ with an aldehyde has been studied: a) W. H. Stevenson III, J. C. Martin, J. Am. Chem. Soc. 1985, 107, 6352; An hexavalent complex of 1 with phenanthroline was also isolated: b) W. B. Farnham, J. F. Whitney, J. Am. Chem. Soc. 1984, 106, 3992.

[10] F. Medici, G. Gontard, E. Derat, G. Lemière, L. Fensterbank, Organometallics. 2018, 37, 517.

[11] For other abnormal adducts featuring a pentacoordinate silicon, see: a) Y. Wang, Y. Xie, P. Wei, H. F. Schaefer III, G. H. Robinson, Dalton Trans. 2016, 45, 5941; b) P. A. Singh, R. S. Ghadwal, H. W. Roesky, J. J. Holstein, B. Dittrich, J.-P. Demers, V. Chevelkovb, A. Lange, Chem. Commun. 2012, 48, 7574.

[12] a) B. M. Day, K. Pal, T. Pugh, J. Tuck, R. A. Layfield, Inorg. Chem 2014, 53, 10578; b) B. M. Day, T. Pugh, D. Hendriks, C. Fonseca Guerra, J. Evans, F. M. Bickelhaupt, R. A. Layfield, J. Am. Chem. Soc 2013, 135, 13338; c) R. H. Crabtree, Coordination Chemistry Reviews 2013, 257, 755

[13] M. Uzelac, A. Hernan-Gomez, D. R. Armstrong, A. R. Kennedy, E. Hevia, Chem. Sci. 2015, 6, 5719

[14] G. Schnee, O. N. Faza, D. Specklin, B. Jacques, L. Karmazin, R. Welter, C. Silva Lopez, S. Dagorne, Chem. Eur. J. 2015, 21, 17959.

[15] a) M. A. Beckett, G. C. Strickland, J. R. Holland, K. S. Varma, Polymer 1996, 37, 4629; b) V. Gutmann, Coord. Chem. Rev. 1976, 18, 225.

[16] For a $A N$ of $B\left(C_{6} F_{5}\right)_{3}$ in the literature, see: A. Ashley, T. J. Herrington, G. G. Wildgoose, H. Zaher, A. L. Thompson, N. H. Rees, T. Krämer, D. O'Hare, J. Am. Chem, Soc. 2011, 133, 14727.

[17] G. Ung, G. Bertrand, Chem. Eur. J. 2011,17, 8269.

[18] P. A. Chase, D. Stephan, Angew. Chem. Int. Ed. 2008, 47, 7433.

[19] G. Bistoni, A. A. Auer, F. Neese, Chem. Eur. J. 2016, 23, 865.

[20] D. Tofan, F. P. Gabbaï, Chem. Sci. 2016, 7, 6768

[21] See supporting information for full details.

[22] For very recent contributions, see: a) X. Ren, H. Du, J. Am. Chem. Soc. 2016, 138, 810; b) M. Lindqvist, K. Borre, K. Axenov, B. Kótai, M. Nieger, M. Leskelä, I. Pápai, T. Repo, J. Am. Chem. Soc. 2015, 137, 4038.

[23] For a review on silicon-stereogenic silanes in asymmetric synthesis, see: L.-W. Xu, L. Li, G.-Q. Lai, J.-X. Jiang, Chem. Soc. Rev. 2011, 40 1777 . 


\section{COMMUNICATION}

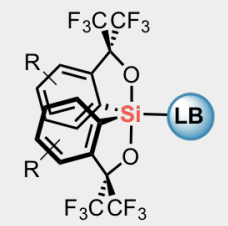

Lewis Base

Normal Lewis Adduct

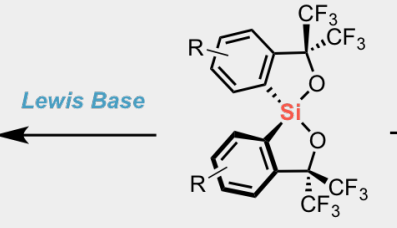

Tetravalent Silicon(IV)

Lewis Acid

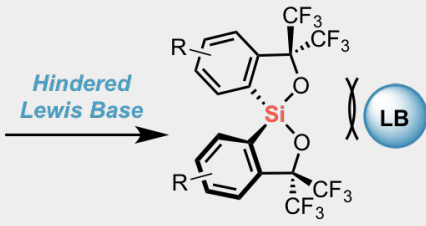

FLP Type Reactivity

Herein, we report on the interaction between hindered Lewis bases and spirosilane derivatives. Normal and abnormal Lewis adducts were selectively isolated using $\mathrm{N}$-Heterocyclic Carbenes, by tuning the Lewis acidity of the Lewis acid partner. Some FLP-type reactivities are also presented.

Fabrizio Medici, Julien Maury, Gilles

Lemière* and Louis Fensterbank*

Page No. - Page No.

Interaction between Spirosilanes and Lewis Bases: from Coordination to Frustration 